\title{
Multi Temporal Satellite Images for Growth Detection and Urban Sprawl Analysis; Dubai City/UAE
}

\author{
Diena Aldogom ${ }^{\mathrm{a}}$, Nour Aburaed ${ }^{\mathrm{a}}$, Mina Al-Saad ${ }^{\mathrm{a}}$, Saeed Al Mansoori ${ }^{\mathrm{b}}$, Meera Rashid Al \\ Shamsi $^{\mathrm{b}}$, and Alya Ahmed AlMaazmi ${ }^{\mathrm{b}}$ \\ anniversity of Dubai, Dubai, UAE \\ ${ }^{\mathrm{b}}$ Mohammed Bin Rashid Space Center, Dubai, UAE
}

\begin{abstract}
Urbanization is a spatiotemporal process that has significant role in economic, social, and environmental structures. Spatiotemporal analysis for urban growth is vital for city management planning. With highly recognized financial and social developing trends, Dubai City, UAE appears as one of most challenging cities in terms of research and preparation toward a smart city aspect. Integrated technologies of remote sensing and geographic information system (GIS) facilitate urban growth detection and its relation to population distribution. In this study Multi-temporal, medium-resolution Landsat images were used to detect and analyze the urbanization trend in Dubai over the last three decades(1986-2019). Moreover, the influence of urbanization on the aspects of smart city tendency was investigated. The study methodology consisted of three parts. First, classification algorithms along with change detection, segmentation, and extraction of urban areas were used to obtain land Use/land Cover (LULC) maps. Second, Shannon's entropy was used to investigate Dubai's growth toward compact or sprawl city based on two city centers and a major highway. Finally, CA-Markov, associated with the digital elevation model and road map of Dubai, was used to simulate the urban change for 2030, 2050, and 2100. With more than $90 \%$ overall accuracy, the statistical analysis for LULC percentages and Shannons entropy values indicated that Dubai experienced a considerable increase in urban fabric while maintaining a compact growth. CA-Markov model estimated 3\% urban growth by 2030, which would result in potential loss of green areas and open spaces. This study could be used in improving planning and management methods to achieve sustainable urban growth.
\end{abstract}

Keywords: Spatiotemporal analysis, Landsat, land Use/land Cover, sprawl analysis, Shannons entropy, image classification

\section{INTRODUCTION}

One of the main challenges that governments and different planning organizations worldwide face is the rapid population growth in urban areas, particularly in developed cities. According to the United Nations (2018), the worlds urban population is expected to increase to $68 \%$ by 2050 , and most of that increase will occur in Asia and Africa,. ${ }^{1}$ Therefore, different towns and cities are expected to expend outside their governmental boundaries. Effective and well-organized governance and planning are needed to achieve sustainable and smart urban development; decrease the pressure on different resources; and reduce undesirable environmental, social, and economic impacts. ${ }^{2}$ At present, ineffective planning policies of the government has resulted in urban sprawl with scattered low density, car-dependent communities, and huge widespread highway networks ${ }^{3}$ ); urban sprawl can be recognized as the primary urban development pattern worldwide. ${ }^{4,5}$

It is considered an obstacle for sustainable development, which causes serious long- and short-term problems, such as extreme infrastructure expenses, economic inefficiency, environmental destruction ${ }^{6}$ and traffic congestion. ${ }^{7}$ Furthermore, urban sprawl can reduce social unity, which affects public safety and security. ${ }^{8}$ At present, new approaches and techniques have been established in observing and examining urban sprawl and its effect to

Further author information :

D. A.: E-mail: daldogom@ud.ac.ae

N. A.: E-mail: noaburaed@ud.ac.ae

M. A.: E-mail: malsaad@ud.ac.ae 
maintain sustainable urban development, such as compact urban growth. ${ }^{9,10}$

Researchers worldwide used remote sensing, geographic information system (GIS), and multiple statistical procedures to map, monitor, analyze and estimate the spatial and temporal changes in urban expansion. ${ }^{9,11-13}$ The availability of spatial data, the advances in remote sensing technologies, and the effective analysis using GIS technology improve and encourage the study of urban spatial patterns and changes over time. ${ }^{14,15}$ These studies are beneficial to define the present and future requirements of any country and manage the limited natural resources and the costs behind building new infrastructure. With different techniques for measuring and mapping urban patterns, Shannon's entropy can be considered an effective measure to urban sprawl and compactness in any city ${ }^{11,16}$ which can improve governmental management and planning procedures. Dubai, with highly recognized financial and socially developing trends, hundred times population growth since 1950, and four hundred times urban fabric amplification, appears as one of most challenging cities in terms of research and preparation toward a smart city aspect. Understanding and observing the urban growth and LULC changes within Dubai emirate is vital and useful for the municipality planners and policymakers to achieve effective valuable developments. ${ }^{10,17}$ TTherefore, the first objective of this study is to use Shannon's entropy along with remote sensing and GIS techniques to measure Dubai's urban sprawl in the years 1986, 1998, 2008, and 2019. The second objective is to investigate LULC changes over the period of 1986-2019, , where Dubai experienced a rapid growth. Finally, this study aims to estimate future urban growth and LULC changes in 2030, 2050, and 2100. This begins by introducing the study area and the datasets used. This paper starts with introducing the study area, and the used datasets. Sec.3 provides a detailed methodological framework of image classification, Shannon's entropy, and CA-Markov urban growth estimation. Sec.4 reports and discusses urban sprawl results and the assessment of Shannon's entropy. Finally, Sec.5 concludes the study.

\section{MATERIALS}

\subsection{Study Area}

This study focuses on the LULC changes and sprawl analysis of Dubai Emirate. Dubai is one of the seven emirates in United Arab Emirates (UAE);it is located at $25.2697^{\circ} \mathrm{N} 55.3095^{\circ} \mathrm{E}$,Figure.1, and covers an area of $4,110 \mathrm{~km}^{2}$ at the southeast coast of Arabian Gulf. ${ }^{18}$ Dubai is considered the largest, most populated emirate in UAE according to the Statistics Center of Dubai. Over the last 30 years, Dubai had experienced rapid population growth from 3370,788 in 1985 to more than 3 million in 2018. ${ }^{19}$ Analyzing urban trends and predicting the changes in Dubai City can provide valuable and effective data for municipality planners and policymakers to insure Dubais urban growth toward a smart, sustainable city.

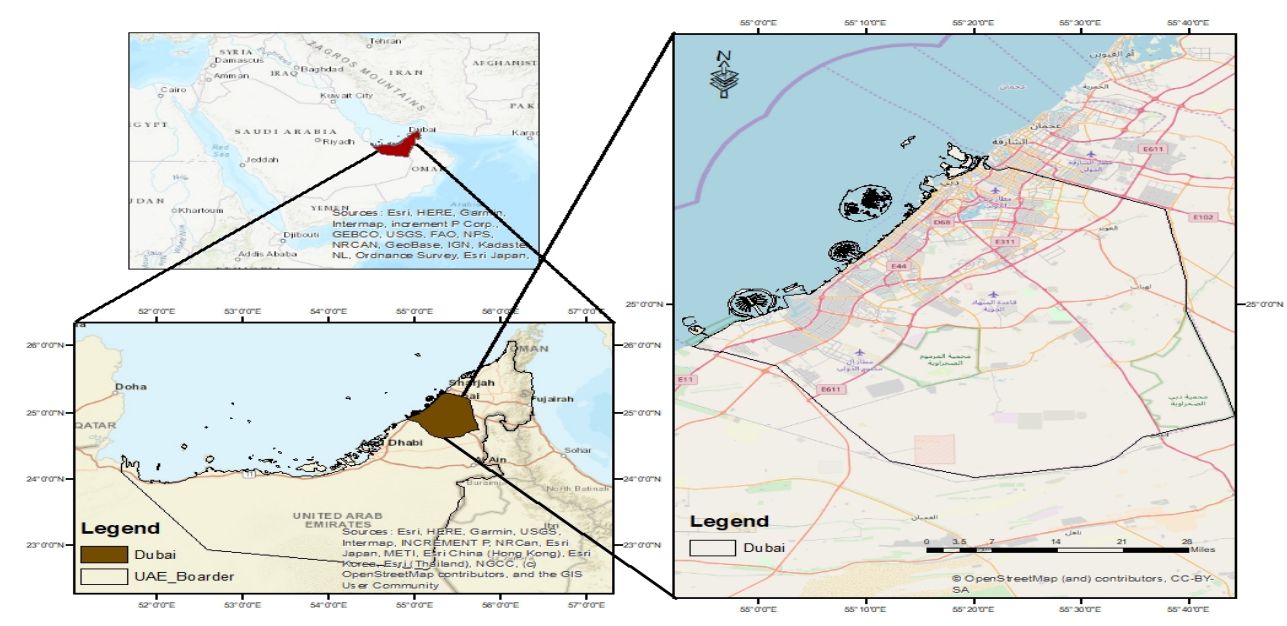

Figure 1: Study area location map. 


\subsection{Data Sets}

Landsat satellite images with less than $10 \%$ cloud coverage for the years 1986, 1989, 2008, and 2019, along with Dubai 30m DTM, were downloaded for free from the United States Geology Survey website to be used in this study, Table.1 Dubai street maps were obtained from the open street maps. Dubai boundary shape files and LULC maps were obtained from Mohammed Bin Rashid Space Center in Dubai.

Table 1: Information of used satellites imagery.

\begin{tabular}{|l|l|l|l|l|}
\hline Satellite & Date & Sensor & $\begin{array}{l}\text { Spatial reso- } \\
\text { lution }\end{array}$ & Projection \\
\hline Landsat 5 & $1986-$ 01- 13 & $\begin{array}{l}\text { Multispectral Scanner } \\
\text { (MMS) }\end{array}$ & $60 \mathrm{~m}$ & $\begin{array}{l}\text { WGS84 UTM Zone } \\
43 \mathrm{~N}\end{array}$ \\
\hline Landsat 5 & $1998-02-15$ & Thematic Mapper (TM) & $30 \mathrm{~m}$ & $\begin{array}{l}\text { WGS84 UTM Zone } \\
43 \mathrm{~N}\end{array}$ \\
\hline Landsat 5 & $2008-05-17$ & Thematic Mapper (TM) & $30 \mathrm{~m}$ & $\begin{array}{l}\text { WGS84 UTM Zone } \\
43 \mathrm{~N}\end{array}$ \\
\hline Landsat 8 & 2019-03-25 & $\begin{array}{l}\text { Operational Land Image } \\
\text { (OLI) and Thermal In- } \\
\text { frared Sensor (TIRS) }\end{array}$ & $30 \mathrm{~m}$ & $\begin{array}{l}\text { WGS 84 UTM Zone } \\
43 \mathrm{~N}\end{array}$ \\
\hline
\end{tabular}

\section{METHODOLOGY AND WORK FRAME}

\subsection{Image Preprocessing and Classification}

Removing the effect of the atmosphere is an essential stage to precisely extract land information from satellite images. $^{20}$ Landsat images were atmospherically corrected using ENVI, and the haze component was removed using the Dark Object Subtraction method. After creating multiple Landsat composite images, unsupervised classification based on ISO cluster classifier in ArcPro was used to classify the satellite images. Localized neighborhoods of pixels were classified and grouped together using a segmentation process that considers the spatial and spectral details within the images. Finally, the reclassified maps were overlaid with different aerial images, Google Earth maps, and the available high-resolution Dubai Landsat images to manually edit the misclassified pixels. Four land cover classes, namely, urban, agriculture, desert, and water, were recognized and generated, Tab.2.

Table 2: Description of the generated classes by the classification method.

\begin{tabular}{|c|c|c|}
\hline Class number & Class name & Description \\
\hline 1 & Desert & Sand area \\
\hline 2 & Urban & Roads, Residential, commercial, and industrial buildings \\
\hline 3 & Agriculture & Green areas \\
\hline 4 & Water & Water bodies \\
\hline
\end{tabular}

\subsection{LULC Accuracy Assessment}

Accuracy assessment is important after classification to provide accurate and effective analysis of LULC changes. ${ }^{21}$ The accuracies of the classified images were tested using 500 randomly scattered points. Error matrixes were generated to compare the relationship between the known ground truth and the classified image. Accuracy measurements, including overall accuracy (OA) and kappa index of agreement, were used to evaluate the classified images. 


\subsection{Change Detection}

Pixel cross tabulation analysis was used to define and quantify LULC deviations during the four time intervals (i.e. 1986-1998, 1998-2008, 2008-2019 and 1986-2019).

\subsection{Shannon's Entropy for Dubai's Urban Growth}

In this study, the effective method of Shannons entropy Eq. $1,{ }^{22}$ along with relative Shannon's entropy Eq.2 $2^{23}$ , were used to identify and measure the amount of compactness or sprawl in Dubai for more than thirty years 1986-2019 as), as shown as follows:

$$
H_{n}=-\sum_{i}^{n} P_{i} \log \left(\frac{1}{P_{i}}\right)
$$

$P_{i}$ is the probability or proportion of a phenomenon, occurring in the $i^{\text {th }}$ zone.

$$
H_{n}=-\sum_{i}^{n} P_{i} \frac{\log \left(\frac{1}{P_{i}}\right)}{\log (n)}
$$

Shannon's entropy values ranges from 0 to $\log (n)$. Higher-density urban zones can be connected to values closer to zero, whereas scattering urban growth was connected to values closer to $\log (n) .{ }^{22}$ Meanwhile, relative Shannons entropy value ranges from 0 to 1 , where 0 and 1 represent compact and sprawl areas, respectively. In this study, Shannon's entropy was measured by generating multiple buffering zones using ArcGIS software to cover the entire developed area within Dubai City from three centers as follows, Figure.2:

- Deira City Center, which was Dubais city center until 2008;

- Burj Khaliafh City Center, which is the current city center of Dubai; and

- E11 Road, which is the first main highway in Dubai.

\subsection{Urban Change Modeling and Validation Using CA-Markov}

CA-Markov is an effective method for simulating future urban developments. ${ }^{24}$ CA-Markov model is a Markov chain model, combined with cellular automata and multi- criteria and multi- objective land allocation, that effectively predicts land cover by adding a spatial contiguity element and the knowledge of the likely spatial distribution of transitions to Markov chain analysis. ${ }^{25}$ CA-Markov model generates transition probability and transition area matrixes. The transition probability matrix analyzes the possible change in each pixel of the LULC map with time, whereas the transition area matrix shows the number of changed pixels over time. CAMarkov model in IDRISI was used for LULC simulation in Dubai. First, classified images (1986, 1998, 2008 and $2019)$ ) were used to compute transition probability matrixes of the LULC change for 1986-1998, 1998-2008, and 2008-2019. Second, transition suitability maps were created using different weighted indicators (e.g., elevation, slope, distance to the road, and distance to urban areas) to be used along with the transition probability matrixes in the simulation process of 2030, 2050, and 2100 future LULC maps. Finally, the neighborhood pixels were defined using a contiguity filter (kernel size of $5^{*} 5$ pixels). In the validation process, the predicted map of 2019 was compared with the classified image of 2019 using ArcGIS and the VALIDATE module in IDRISI.

\section{RESULTS AND ANALYSIS}

\subsection{LULC Accuracy Assessment}

Error matrixes were utilized to measure and address the classification accuracies using ISO cluster classifier with an unsupervised classification method. OAs for the classified maps of 1986, 1998, and 2008 are 99\%, 98\%, 96\%, and Kappa coefficients are $93 \%, 87 \%, 85 \%$, respectively,Tables. 3-5,in which $85 \%$ is considered the minimum acceptable accuracy value. ${ }^{26}$ 


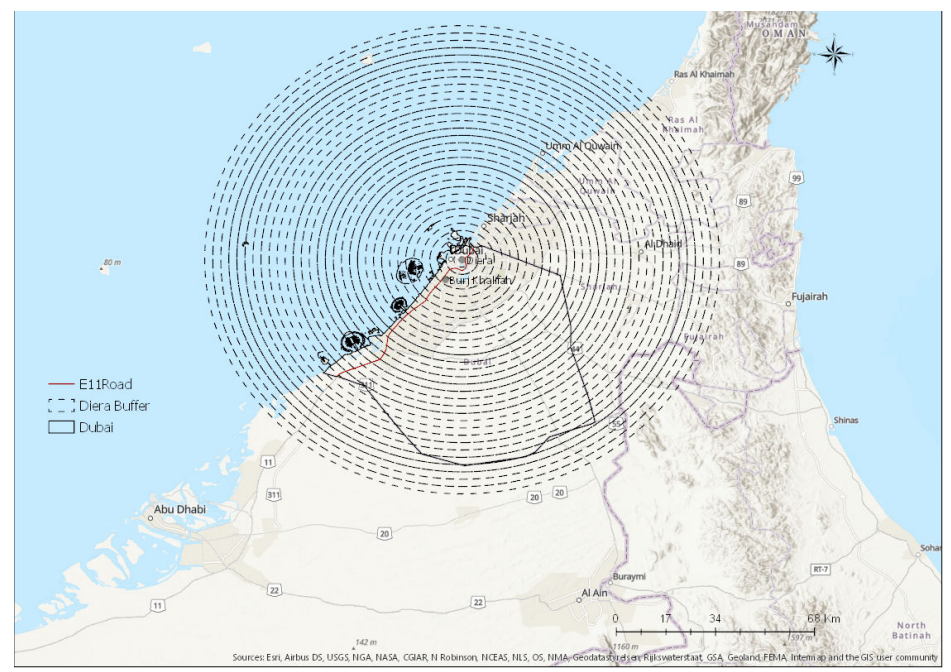

(a)

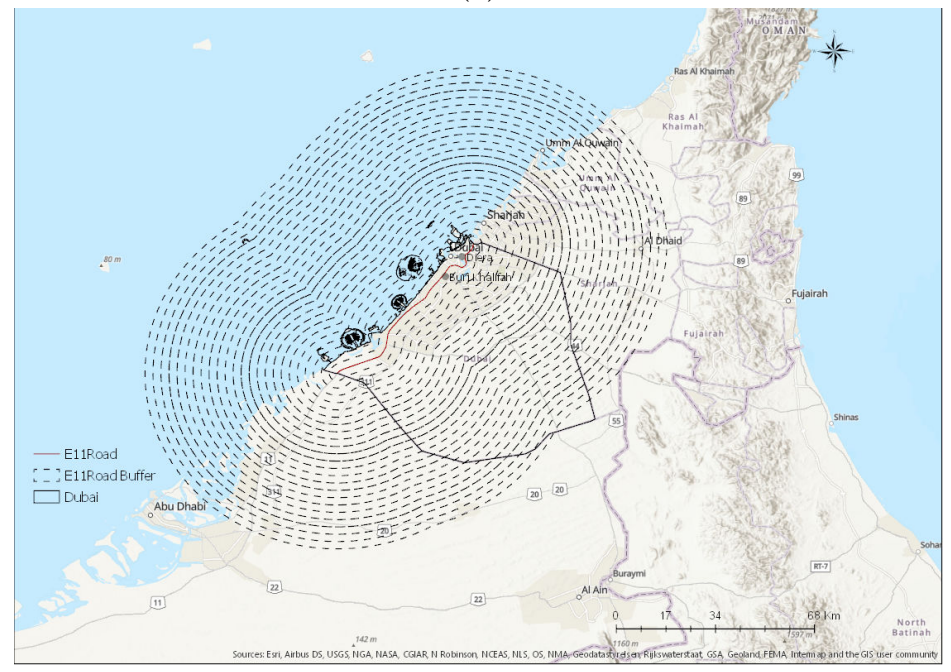

(b)

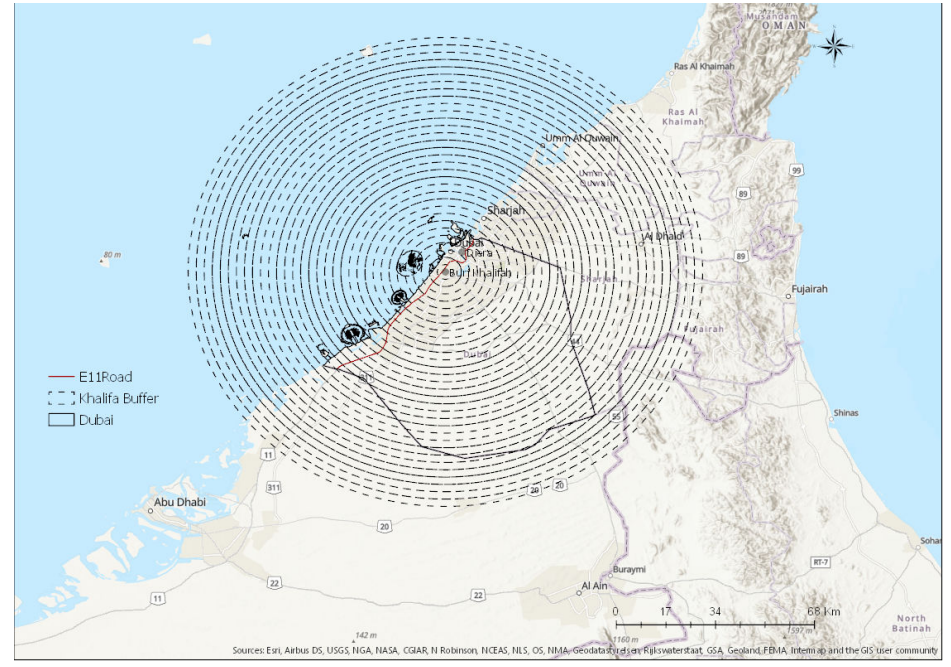

(c)

Figure 2: Multiple buffering zones from different city center(a)Deria, (b)E11,(c) BurjKhalifh. 
Table 3: Error matrix for the classified image of 1986 to the ground truth.

\begin{tabular}{|l|l|l|l|l|l|l|l|l|}
\hline ObjectID & Classvalue & C_1 & C_2 & C_3 & C_4 & Total & U_Accuracy & Kappa \\
\hline 1 & C_1 & 452 & 1 & 0 & 0 & 453 & 0.997792 & 0 \\
\hline 2 & C_2 & 1 & 8 & 0 & 0 & 9 & 0.88889 & 0 \\
\hline 3 & C_3 & 1 & 0 & 4 & 0 & 5 & 0.8 & 0 \\
\hline 4 & C_4 & 0 & 0 & 0 & 10 & 10 & 1 & 0 \\
\hline 5 & Total & 454 & 9 & 4 & 10 & 477 & 0 & 0 \\
\hline 6 & P_Accuracy & 0.995595 & 0.888889 & 1 & 1 & 0 & 0.993711 & 0 \\
\hline 7 & Kappa & 0 & 0 & 0 & 0 & 0 & 0 & 0.933952 \\
\hline
\end{tabular}

Table 4: Error matrix for the classified image of 1998 to the ground truth.

\begin{tabular}{|l|l|l|l|l|l|l|l|l|}
\hline ObjectID & Classvalue & C_1 & C_2 & C_3 & C_4 & Total & U_Accuracy & Kappa \\
\hline 1 & C_1 & 455 & 2 & 0 & 0 & 457 & 0.995624 & 0 \\
\hline 2 & C_2 & 0 & 20 & 0 & 0 & 20 & 1 & 0 \\
\hline 3 & C_3 & 7 & 1 & 4 & 0 & 12 & 0.333333 & 0 \\
\hline 4 & C_4 & 0 & 0 & 0 & 11 & 11 & 1 & 0 \\
\hline 5 & Total & 462 & 23 & 4 & 11 & 500 & 0 & 0 \\
\hline 6 & P_Accuracy & 0.984848 & 0.869565 & 1 & 1 & 0 & 0.98 & 0 \\
\hline 7 & Kappa & 0 & 0 & 0 & 0 & 0 & 0 & 0.869237 \\
\hline
\end{tabular}

Table 5: Error matrix for the classified image of 2008 to the ground truth.

\begin{tabular}{|l|l|l|l|l|l|l|l|l|}
\hline ObjectID & Classvalue & C_1 & C_2 & C_3 & C_4 & Total & U_Accuracy & Kappa \\
\hline 1 & C_1 & 412 & 6 & 0 & 0 & 418 & 0.985646 & 0 \\
\hline 2 & C_2 & 8 & 41 & 0 & 0 & 49 & 0.836735 & 0 \\
\hline 3 & C_3 & 3 & 0 & 9 & 0 & 12 & 0.75 & 0 \\
\hline 4 & C_4 & 1 & 0 & 0 & 9 & 10 & 0.9 & 0 \\
\hline 5 & Total & 424 & 47 & 9 & 9 & 489 & 0 & 0 \\
\hline 6 & P_Accuracy & 0.971698 & 0.87234 & 1 & 1 & 0 & 0.96319 & 0 \\
\hline 7 & Kappa & 0 & 0 & 0 & 0 & 0 & 0 & 0.851788 \\
\hline
\end{tabular}

\subsection{LULC Change and Urban Growth}

During the last three decades, Dubai had encountered a rapid urban growth Tables. 6-7, and Fig. 3. The study analysis on LULC change detection shows that during the first time period (1986-1998), ), urban area has increased by more than $59 \mathrm{~km}^{2}$, which is $1.5 \%$ of Dubais area Tab. 6. In 1986, the urban area covered $2.4 \%$ of the study area, whereas approximately $94 \%$ and $2 \%$ were covered by desert and agricultural lands, respectively.However, the 1998 LULC map shows that $155 \mathrm{~km}^{2}$ was covered by urban area (4\% of Dubai's area); during the same time period, desert land decreased to $94 \mathrm{~km}^{2}$, (2\% of Dubais area). The percentage of urban area over the first time period has doubled. In 2008, the urban area continued to grow and expand to cover 392 $\mathrm{km}^{2}$ (10\% of Dubais area), whereas desert lands decreased by $4 \%$. Throughout the third time period (2008-2019), ), Dubai showed an expansion in the urban area that reached $309 \mathrm{~km}^{2}$ (7\% of Dubais area), and a reduction in desert land reached $9 \%$. From 1986 to 2019, more than $644 \mathrm{~km}^{2}$ of desert land were converted to urban areas. 
Comparison of the last and first time periods show that a rapid urban growth of $309 \mathrm{~km}^{2}$ (compared to $59 \mathrm{~km}^{2}$ ) could be observed; this growth, combined with a considerable decrease in the desert land reached 16\% (Fig. 3 and Tab.7).

Table 6: LULC areas of Dubai during the study time period.

\begin{tabular}{|c|c|c|c|c|c|c|c|c|}
\hline Classes & $1986 \mathrm{~km}^{2}$ & $1986(\%)$ & $1998 \mathrm{~km}^{2}$ & $1998(\%)$ & $2008 \mathrm{~km}^{2}$ & $2008(\%)$ & $2019 \mathrm{~km}^{2}$ & $2019(\%)$ \\
\hline Desert & 3677.07 & $93.84 \%$ & 3582.49 & $91.45 \%$ & 3397.61 & $86.72 \%$ & 3032.59 & $77.4 \%$ \\
\hline Urban & 95.94 & $2.45 \%$ & 155.11 & $3.96 \%$ & 392.62 & $10.02 \%$ & 702.49 & $17.93 \%$ \\
\hline Agriculture & 65.03 & $1.66 \%$ & 97.64 & $2.49 \%$ & 95.61 & $2.44 \%$ & 140.65 & $3.59 \%$ \\
\hline Water & 20.038 & $2.05 \%$ & 82.26 & $2.01 \%$ & 32.08 & $0.82 \%$ & 42.34 & $1.08 \%$ \\
\hline
\end{tabular}

Table 7: LULC change in areas during the study time period.

\begin{tabular}{|c|c|c|c|c|c|c|}
\hline Classes & $1986-1998$ & Difference (\%) & $1998-2008$ & Difference (\%) & $2008-2019$ & Difference (\%) \\
\hline Desert & -94.57 & -2.39 & -184.89 & -4.73 & -365.03 & -9.32 \\
\hline Urban & 59.17 & 1.51 & 237.51 & 6.06 & 309.88 & 7.91 \\
\hline Agriculture & 32.61 & 0.83 & -2.03 & -0.05 & 45.04 & 1.15 \\
\hline Water & 62.22 & 0.05 & -50.18 & -1.28 & 10.26 & 0.26 \\
\hline
\end{tabular}

\subsection{Urban Growth in Dubai}

In this study, Shannon's entropy $H_{n}$ was used to investigate the level of urban spreading or compactness within Dubai Emirate by generating 24 zones with a radius of a $2.5 \mathrm{~km}$ Dubais two city centers (i.e.,Deira in 1986-2008, and Burj Khalifah in 2019), and 32 zones with the same radius from E11 Road. Shannon's entropy for the entire time period measured using the different zones was less than half of $\log (24)$ and half of $\log (32)$, Tab.8 Thus, Dubai maintained a compact urban growth along the study period (Bhatta et al., 2009). In 1986, relative Shannon's entropy value was the least (i.e.,0.14 in E11 Road and 0.19 in Deira), where as the largest value was calculated in 2019(i.e., 0.33 in Deira). Hence, in 1986, the city was more compact compared with 2008. However, the city center was changed from Deira to Burj Khalifh, which lowered the relative Shannon's entropy value in 2019 from 0.33 to 0.32 and helped the city to maintain a compact urban growth. Finally, when relative Shannon's entropy was calculated using multiple zones from E11Road, Dubai kept a compact urban growth along the highway.

Table 8: Shannon's entropy and relative Shannon's entropy values

\begin{tabular}{|c|c|c|c|c|c|c|}
\hline \multirow{2}{*}{ Years } & \multicolumn{3}{|c|}{ Shannon's entropy } & \multicolumn{3}{c|}{ Relative Shannon's entropy } \\
\cline { 2 - 7 } & Deira & Burj Khalifah & E11 & Deria & Burj Khalifah & E11 \\
\hline 1986 & 0.668606745 & - & 0.440348097 & 0.192919127 & - & 0.138559043 \\
\hline 1998 & 0.805909206 & - & 0.63907276 & 0.232536243 & - & 0.201089344 \\
\hline 2008 & 0.960822042 & - & 0.708054192 & 0.277234639 & - & 0.222794902 \\
\hline 2019 & 1.12785194 & 1.106088522 & 0.948152384 & 0.32542928 & 0.319149685 & 0.298343714 \\
\hline
\end{tabular}

\subsection{LULC Simulation and Validation}

Classified LULC maps for 1998 and 2008 were used to simulate 2019 LULC map. Classified 2019 LULC map was compared to the simulated one to validate the model as an important process in the simulation. The simulated 


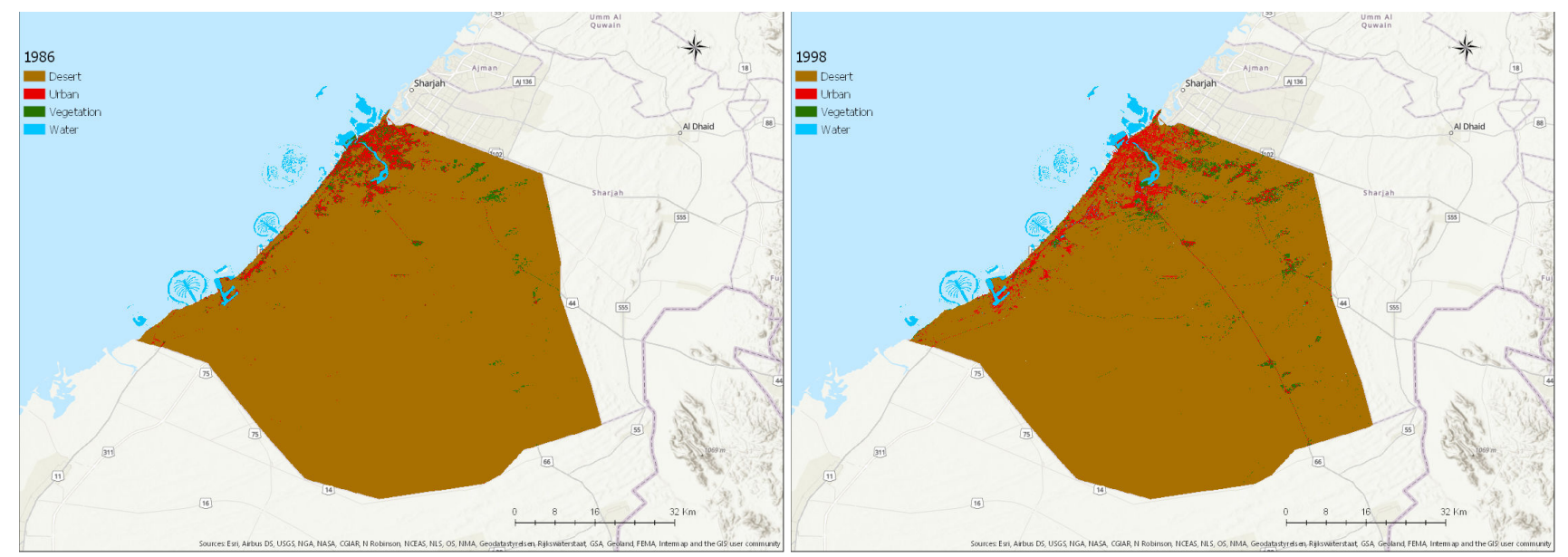

(a)

(b)

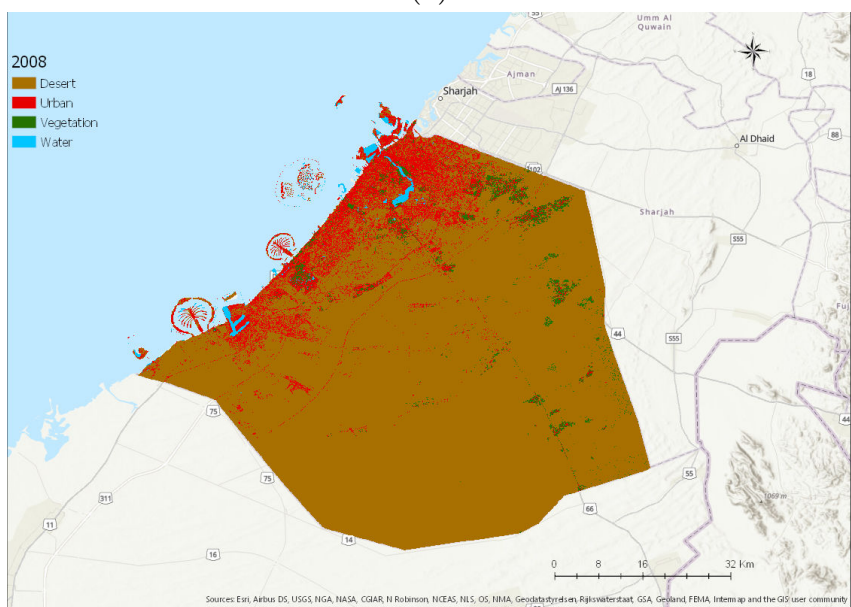

(c)

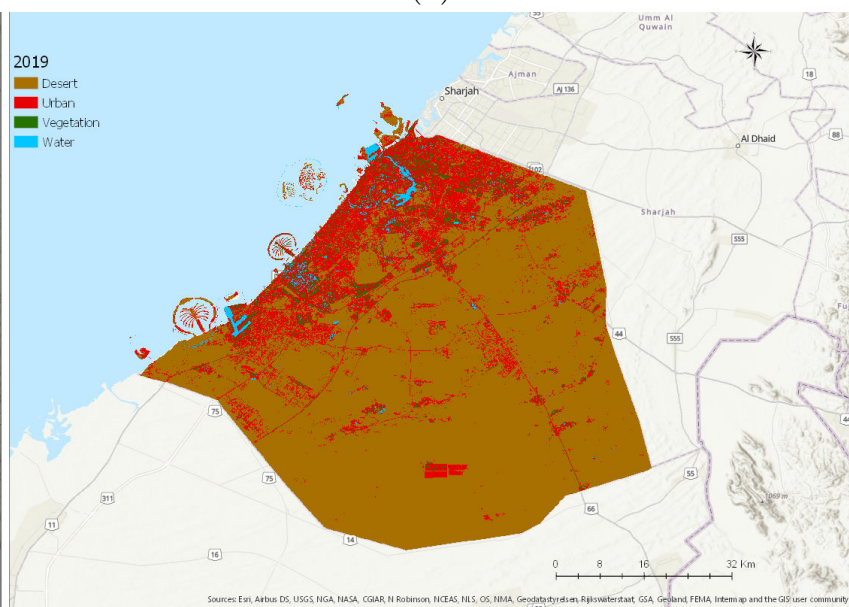

(d)

Figure 3: Dubai's land cover changes during the study time period (a)1986, (b)1998, (c)2008, and(d)2019. 
LULC for 2019 agrees well with the classified LULC map of 2019. Kappa spatial correlation statistic reveals a good level of agreement between the classified map of 2019 and the simulation output map (more than 81\%). Therefore, CA-MARKOV transition probability matrixes, along with weighted slope, distance from the roads, and distance from urban area maps, could be used to simulate the urban growth in Dubai for the following years(i.e., 2030, 2050, and 2100), Figure. 4 The simulation shows thaturban areas will increase by $3 \%, 7 \%$, and $19 \%$ in 2030, 2050, and 2100, respectively, Tab. 9.

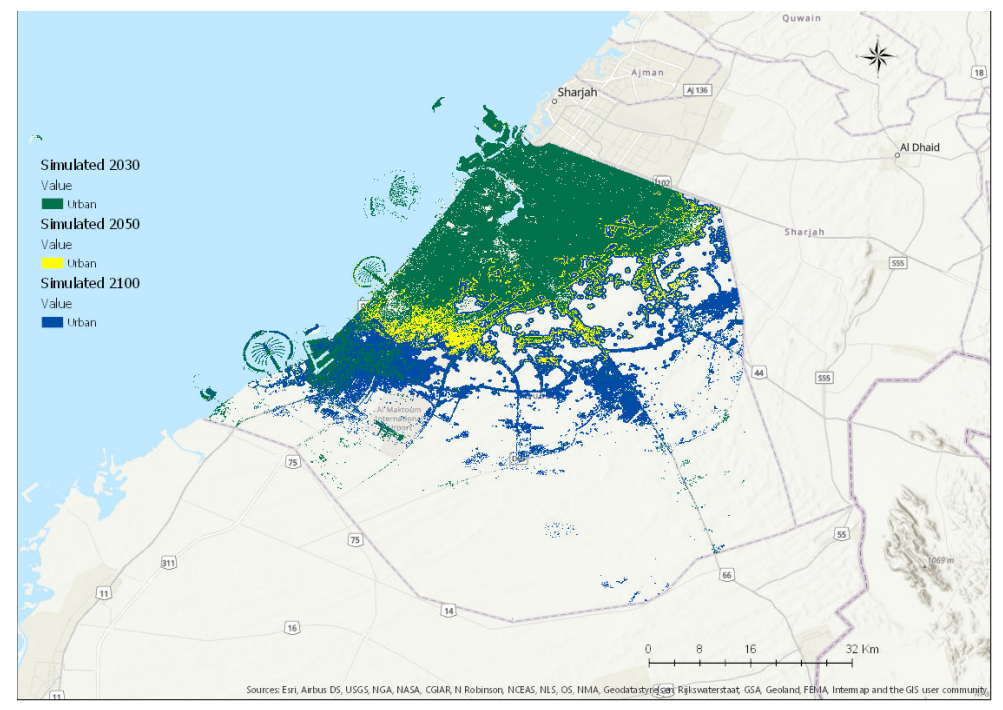

Figure 4: Land cover land use simulation results.

Table 9: Urban growth estimation using CA-Markov

\begin{tabular}{|l|l|l|l|}
\hline $\begin{array}{c}\text { Simulation } \\
\text { year }\end{array}$ & Area & Percentage & Differences \\
\hline 2019 & 689.16 & $18 \%$ & - \\
\hline 2030 & 816.37 & $21 \%$ & $29 \%$ \\
\hline 2050 & 967.66 & $25 \%$ & $6 \%$ \\
\hline 2100 & 1434.94 & $37 \%$ & $19 \%$ \\
\hline
\end{tabular}

\section{CONCLUSION}

LULC change can frequently vary due to urbanization, especially in developing countries; this phenomenon results in urban sprawl. Mapping, analyzing, and monitoring urban growth can effectively help policymakers and planners to easily identify threatened areas and solve problems. In this study, Dubai LULC change was analyzed over more than three decades (1986-2019). Urban sprawl and compactness were examined using Shannon's entropy for two city centers and a major highway. Finally, CA-Markov model was used to simulate future LULC maps of the years 2030, 2050, and 2100. Although further spatial analysis is needed, LULC change detection analysis and Shannons entropy reveal that Dubai's urban development is toward a smart compact growth. The CA-Markov model predicted that urban growth would continue to reach $19 \%$ by 2100 , where desert land would be changed into an urban area. This study could be used as a good reference for urban management and planning services within Dubai City. 


\section{REFERENCES}

[1] United Nations, D. o. E. and Social Affairs, P. D., "2018 revision of world urbanization prospects," (2018).

[2] Basiago, A., "Economic, social, and environmental sustainability in development theory and urban planning practice," The Environmentalist 19, 145-161 (1998).

[3] Zhao, P., "Sustainable urban expansion and transportation in a growing megacity: Consequences of urban sprawl for mobility on the urban fringe of beijing," Habitat International 34(2), 236-243 (2010).

[4] Zanganeh Shahraki, S., S. D. S. P. M. S. S. F. and Pourahmad, A., "Urban sprawl pattern and land-use change detection in yazd, iran," Habitat International 35(4), 521-528 (2011).

[5] Gmez-Antonio, M., H.-R. M. a. L. L., "The causes of urban sprawl in spanish urban areas: A spatial approach," GEN-Governance and Economics Research Network (2014).

[6] Camagni, R., G. M. and Rigamonti, P., "Urban mobility and urban form: The social and environmental costs of different patterns of urban expansion," Ecological Economics 40(2), 199-216 (2002).

[7] Ewing, R., P. R. and Chen, D., "Measuring sprawl and its transportation impacts," Transportation Research Record: Journal of the Transportation Research Board 1831(1), 175-183 (2003b).

[8] Cozens, P., "Public health and the potential benefits of crime prevention through environmental design," New South Wales Public Health Bulletin 18(12), 232-237 (2007).

[9] Turskis, Z., Z. E. and Zagorskas, J., "Sustainable city compactness evaluation on the basis of gis and bayes rule," Journal Of Strategic Property Management 10(3), 185-207 (2006).

[10] Shaw, J., "Sprawl and smart growth," Journal of Environment Law 21, 4374 (2000).

[11] Mosammam, H., N. J.-K. H. T. A. and Kazemi, M., "Monitoring land use change and measuring urban sprawl based on its spatial forms: The case of qom city," The Egyptian Journal Of Remote Sensing And Space Science 20(1), 103-116 (2017).

[12] Fan, F., W. Y.-Q. M. and Wang, Z., "Evaluating the temporal and spatial urban expansion patterns of guangzhou from 1979 to 2003 by remote sensing and gis methods," International Journal of Geographical Information Science 23(11), 1371-1388 (2009).

[13] Liu, T. and Yang, X., "Monitoring land changes in an urban area using satellite imagery, gis and landscape metrics," Applied Geography 56, 4254 (2015).

[14] Herold, M., G. N. and Clarke, K., "The spatiotemporal form of urban growth: Measurement, analysis and modeling," Remote Sensing Of Environment 86(3), 286-302 (2003).

[15] Seto, K. and Fragkias, M., "Quantifying spatiotemporal patterns of urban land-use change in four cities of china with time series landscape metrics," Landscape Ecology 20(7), 871-888 (2005).

[16] Sarvestani, M.S., I. A.-K. P., "Three decades of urban growth in the city of shiraz, iran: A remote sensing and geographic information systems application," Cities 28 (4), 320-329 (2011).

[17] Knox, P., [The Restless Urban Landscape], Englewood Cliffs, N.J. : Prentice Hall (1993).

[18] Wikipedia, "Map of dubai." https://en.wikipedia.org/wiki/Dubai (2019).

[19] Center, D. S., "Population and vital statistics." https://www.dsc.gov.ae/en-us/Themes/Pages/ Population-and-Vital-Statistics . aspx?Theme=42 (2019).

[20] Liang, S., F. H. and Chen, M., "Atmospheric correction of landsat etm+ land surface imagery. i. methods," IEEE Transactions On Geoscience And Remote Sensing 39(11), 2490-2498 (2001).

[21] Butt, A., S. R.-A. S. and Aziz, N., "Land use change mapping and analysis using remote sensing and gis: A case study of simly watershed, islamabad, pakistan," The Egyptian Journal Of Remote Sensing And Space Science 18(2), 251-259 (2015).

[22] Yeh, A. and Xia, L., "Measurement and monitoring of urban sprawl in a rapidly growing region using entropy," Photogrammetric Engineering and Remote Sensing 67(1), 83-90 (2001).

[23] Thomas, R., [Information statistics in geography], Geo Abstracts, Norwich (1981).

[24] White, R. and Engelen, G., "The use of constrained cellular automata for high resolution modelling of urban land-use dynamics," Environment and Planning B: Planning and Design 24, 323-343 (1997).

[25] Sang, L., Z. C.-Y. J. Z. D. and Yun, W., "Simulation of land use spatial pattern of towns and villages based on ca-markov model," Mathematical and Computer Modelling 54, 938-943 (2011).

[26] Anderson, J., [A Land Use and Land Cover Classification System for Use with Remote Sensor Data], United States Government Printing Office, Washington (1976). 